\title{
SUSTAINABLE MANUFACTURING PRACTICES AMONG SMES IN MALAYSIA
}

\author{
Norsiah Hami ${ }^{1 *}$, Fadhilah Mat Yamin ${ }^{1}$, Shafini Mohd Shafie ${ }^{1}$, Mohd Razali Muhamad $^{2}$, \\ Zuhriah Ebrahim ${ }^{2}$ \\ ${ }^{1}$ School of Technology Management and Logistics, Universiti Utara Malaysia, 06010 Sintok, Kedah, \\ Malaysia \\ ${ }^{2}$ Faculty of Manufacturing Engineering, Universiti Teknikal Malaysia Melaka, 76100 Durian \\ Tunggal, Melaka, Malaysia
}

(Received: July 2018 / Revised: September 2018 / Accepted: December 2018)

\begin{abstract}
Small and medium enterprises (SMEs) play a significant role in the economic development of Malaysia, accounting for approximately $97.3 \%$ of businesses in the country. While there is a plethora of studies which examine the commitments of large and multinational firms towards business sustainability, little is known about the efforts of SMEs to translate their strategic orientation towards environmental and social sustainability into action. It is important to examine the extent of SMEs' response to the imperatives of becoming sustainable businesses through the implementation of sustainable manufacturing practice (SMP) in their business operations. The purpose of this paper is to determine the extent of the implementation of SMP among SMEs in Malaysia. Analysing survey data from 127 SMEs, the results show that the extent of the implementation of SMP among them is low to moderate. This implies that although environmental initiatives are becoming important nowadays, there is still a lack of implementation of SMP in the operational and business activities of SMEs in Malaysia. As well as offering some insights into SMP, particularly in the context of SMEs, this study provides a useful reference for salient stakeholders, such as the government and industrial practitioners, for making decisions and taking further action related to the strategies of nurturing, implementing and enforcing environmental protection and social well-being.
\end{abstract}

Keywords: Manufacturing industry; SMEs; Survey; Sustainability; Sustainable manufacturing practice

\section{INTRODUCTION}

Small and medium enterprises (SMEs), which account for a large proportion of businesses, play a significant role in the economic development of developing countries (Koe et al., 2015). In Malaysia, they contributed $32.5 \%$ of gross domestic product (GDP), $19 \%$ of exports, and $57 \%$ of employment (Department of Statistics Malaysia, 2011). SME GDP has grown annually, growing by $6.1 \%$ in 2015 , despite a slight decrease compared to the $7.9 \%$ growth recorded in 2014 (SME Corporation Malaysia, 2016). Unfortunately, while contributing to positive economic values, SMEs have also caused negative effects from their operational and business activities, such as environmental damage (Koe et al., 2015). As argued by Berawi (2016), the challenge for any country is to continue its economic growth and to provide welfare, while ensuring environmental sustainability. In line with the national agenda to become a developed nation, it is crucial for Malaysian SMEs to improve their economic performance at the same 
time as protecting the natural environment and enhancing social well-being.

Sustainable manufacturing practice (SMP) is one of the essential approaches to handling environmental degradation and other sustainability issues. A central principle underlying SMP is its relationship with the sustainability performance of a firm. Recent studies on sustainability management have acknowledged the contributions of SMP to sustainability performance in terms of its abilities to generate greater economic, environmental and social sustainability in firms.

Recognising its importance as a platform for surviving in intense global competition, many manufacturers have increasingly begun to promote and implement sustainable initiatives and practices. Despite the abundance of studies investigating the commitment and initiatives of large and multinational firms towards sustainability in business, little is known about the efforts of SMEs to put their sustainability goals into practice. It is important to determine how well they respond to the imperatives of becoming sustainable businesses, as many firms remain confused about whether and how they should internalize natural environmental and social considerations into their core business operations.

Recently, Khatri and Metri (2016) claimed that SMEs are slow to implement sustainable practice. Developing a sustainable SME business is a great challenge due to the lack of certain important aspects such as innovation and technology, human capital development, market access, access to financing, legal and regulatory frameworks, infrastructure and security (Hashim, 2013). Laurinkeviciute and Stasiskiene (2011) found that SMEs in Lithuania often did not implement any practical measures to reduce their environmental impact. However, examining the environmental practice adoption among SMEs in the manufacturing industry in Auckland, Cassells and Lewis (2011) found that majority of the responding firms did consider the environmental impact of their business activities. Hence, it can be concluded that the responsibility of SMEs to be environmentally friendly and socially responsible is still questionable.

In Malaysia, several studies have been conducted on the implementation of sustainable manufacturing practice in SMEs. Most of these have tended to focus on specific contexts, such as green practice (e.g. Wooi \& Zailani, 2010; Yahya et al., 2014) or social responsibility practice (e.g. Nejati \& Amran, 2013; Yusoff \& Adamu, 2016). Therefore, by considering sustainable manufacturing practice in a wider context, including both environmental and socially responsible practices, this paper aims to examine the extent of the implementation of SMP among SMEs in the Malaysian manufacturing sector.

The following section explains the concepts of sustainability, sustainable manufacturing, stakeholder theory and SMP, and is followed in Section 3 by an explanation of the research method employed. The results of the study are presented and further discussed in Section 4. The paper concludes with the implications, and recommendations for expanding the scope of the study in future research.

\section{LITERATURE REVIEW}

\subsection{Sustainable Manufacturing and Sustainability}

Manufacturing firms in the $21^{\text {st }}$ century face increasingly changing business environments due to sustainability issues such as environmental degradation through the depletion of resources, destruction of the ecosystem, and pollution. There is a need to balance economic, environmental, and social sustainability factors in order to achieve real sustainability. Szekely and Knirsch (2005) argue that to optimize their balance, firms should integrate all three of these factors into their business strategies. This will consequently improve sustainability performance (Hahn et al, 2016) and ensure competitiveness in the manufacturing field (Bhanot et al., 2015). 
Failure to strike a balance between efficient economic development and social responsibility will cause environmental damage, which will eventually result in unsustainable development. In order to maintain a balance between economic, environmental and social sustainability, firms need to implement SMP (Hami, 2015).

In order to protect the natural environment, manufacturing firms need to change their manufacturing approaches, not only producing goods with high productivity, but also changing from a single life cycle orientation to a multiple life cycle (closed-loop production). The concepts of manufacturing have evolved from substitution-based traditional manufacturing, and now encompass lean manufacturing, green manufacturing and sustainable manufacturing, which are focused on innovative and 6R (reduce, reuse, recycle, recover, redesign, remanufacture) methodologies (Jayal et al., 2010). The evolution of manufacturing concepts demonstrates the changing manufacturing practices applied by manufacturing firms, from unsustainable to more sustainable approaches.

\subsection{Stakeholder Theory}

During the last decades, increasing sustainability issues have forced manufacturers in various industries to be more responsible, going beyond simple compliance with regulations. As posited by stakeholder theory, firms should not remain exclusively focused on the interests of shareholders, but should also concentrate on the needs of the other stakeholders (Freeman, 1984). Whether a firm is able or unable to achieve its goals depends on the way it manages its connections with individuals or groups, such as employees, suppliers and communities, who can affect the accomplishment of these goals (Freeman \& Phillips, 2002; Ditlev-Simonsen \& Wenstøp, 2013). From the stakeholder perspective, it is essential to note that a business does not just concern the firm itself, but it should be considered as an integral part of society. As a result, sustainable manufacturing practices, which integrate economic, environmental and social concerns into operational and business activities, have been increasingly accepted and adopted by forward-thinking firms. In doing business, firms need to be environmentally friendly and socially responsible toward their salient stakeholders, such as employees, customers and suppliers.

\subsection{Sustainable Manufacturing Practice (SMP)}

Sustainable manufacturing is a pathway to sustainability. Reviewing the concept, the Organisation for Economic Cooperation and Development (OECD) described the evolution of the sustainable manufacturing concept and practice, from pollution control and treatment, to an integrated business model of industrial ecology, as shown in Figure 1 (OECD, 2010). Every shift in sustainable practices has expanded on the original treatment of pollution, making firms environmentally friendly and socially responsible in the industrial system. Extending firms' limits, the industrial system focuses on life cycle product sharing with external stakeholders, such as the public, social institutions and the environment. There is an argument that the pollution control and treatment approach is unsustainable. For instance, Kim (2010) claims that pollution control has a negative impact on competitiveness as it involves additional cost.

Adapting ideas from Jayal et al. (2010) and OECD (2010), Hami (2015) proposed eight types of SMP, namely cleaner production, eco-efficiency, employee relations, supplier relations, customer relations, community relations, closed-loop production, and industrial relations. The definitions of each practice are shown in Table 1. 


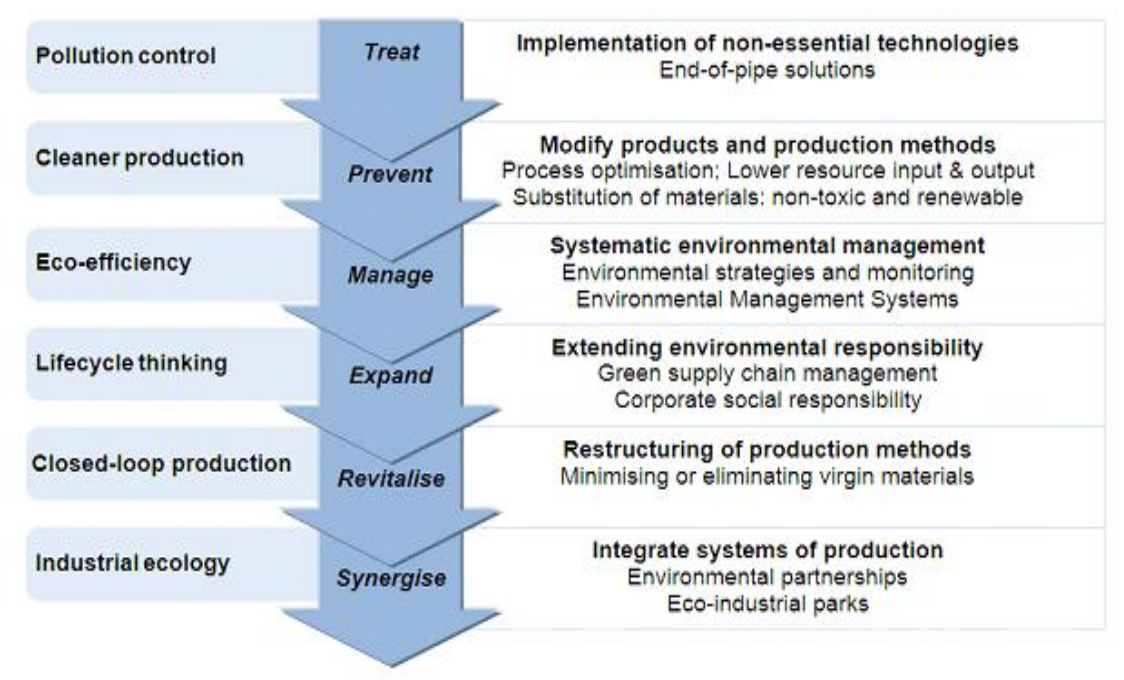

Figure 1 Evolution of the sustainable manufacturing concept/practice (OECD, 2010)

Table 1 Sustainable manufacturing practice (Hami, 2015)

\begin{tabular}{|c|c|}
\hline Practice & Definition \\
\hline Cleaner production & $\begin{array}{l}\text { Preventing pollution at source (in the product and manufacturing processes), rather } \\
\text { than removing it after it has been created }\end{array}$ \\
\hline Eco-efficiency & $\begin{array}{l}\text { Producing more products, simultaneously minimizing resource intensity and } \\
\text { reducing ecological impact in order to increase eco-efficiency }\end{array}$ \\
\hline Employee relations & Implementing a set of plans/programmes to improve employees' well-being \\
\hline Supplier relations & Monitoring and collaborating with suppliers to improve their performance \\
\hline Customer relations & Managing customers to improve their well-being \\
\hline Community relations & Implementing a set of plans/programmes to improve communal performance \\
\hline Closed-loop production & $\begin{array}{l}\text { Closing the material cycle in order to achieve greater sustainability in managing } \\
\text { the supply chain }\end{array}$ \\
\hline Industrial relations & $\begin{array}{l}\text { Collaborating with neighborhood organisations to improve environmental and } \\
\text { social performance }\end{array}$ \\
\hline
\end{tabular}

\subsection{SMP in SMEs}

Environmental initiatives are becoming an important part of the strategic planning of SMEs (Ramayah et al., 2013). Considering the uniqueness of SMEs, the adoption of SMP in their operations is quite different to that of larger firms. By conducting case studies on two Malaysian SMEs, Hami et al. (2017) discovered that certain environmentally and socially responsible practices were implemented by SMEs in the manufacturing sector, such as cleaner production, eco-efficiency, employee relations, supplier relations, and customer relations. As previously mentioned, pollution control is not considered as a sustainable practice, while other practices such as community relations, closed-loop production and industrial ecology are still not fully utilized in SMEs (Hami et al., 2017). Earlier research on the environmental practice of SMEs (Wong \& More, 2016) portrayed them as being more focused on internal rather than community issues. Moreover, they only focused on the $3 \mathrm{R}$ (reduce, reuse and recycle) approach, rather than the more sustainable 6R approach (Hami et al., 2017). SMEs were also unable to practice industrial ecology due to know-how constraints and a lack of technology, finance and resources (Korhonen, 2000).

\section{METHOD}

\subsection{Population and Sample}

The population of the study is manufacturing sector SMEs registered in the directory of the 
SME Corporation Malaysia (SME Corp). Out of the 47,698 SMEs listed, 572 firms were randomly selected as the study sample. The unit of analysis was individual; data were collected from each individual firm and each respondent's response treated as an individual data source. The targeted respondents were carefully selected in order to obtain valid and accurate data. Therefore, considering their level of knowledge, skills and experience in the topic under study, the targeted respondents consisted of personnel holding a managerial position at least at the operational or supervisory level and who were involved in operational activities.

A questionnaire survey approach was used to collect the data. The survey was conducted for about three months between September and December 2017. Overall, 127 responses were received from various manufacturing industries, resulting in a response rate of $22.2 \%$. The characteristics of the responding firms and respondents are shown in Table 2.

Table 2 Characteristics of the responding firms and respondents

\begin{tabular}{|c|c|c|}
\hline Characteristic & Frequency & $\%$ \\
\hline \multicolumn{3}{|l|}{ Number of employees } \\
\hline Fewer than 5 & 44 & 34.6 \\
\hline Between 5 and 75 & 61 & 48.0 \\
\hline More than 75 & 22 & 17.3 \\
\hline \multicolumn{3}{|l|}{ Annual sales turnover } \\
\hline Less than RM300,000 & 72 & 56.7 \\
\hline $\begin{array}{l}\text { Between } \\
\text { million }\end{array}$ & 42 & 33.1 \\
\hline Between RM15 million and RM50 million & 6 & 4.7 \\
\hline More than RM50 million & 7 & 5.5 \\
\hline \multicolumn{3}{|l|}{ Years established } \\
\hline Less than 5 years & 21 & 16.5 \\
\hline $6-10$ years & 33 & 26.0 \\
\hline $11-15$ years & 14 & 11.0 \\
\hline $16-20$ years & 13 & 10.2 \\
\hline More than 20 years & 46 & 36.2 \\
\hline \multicolumn{3}{|l|}{ Job Title/Position } \\
\hline CEO/Managing Director & 73 & 57.5 \\
\hline Manager/Assistant Manager & 30 & 23.6 \\
\hline Executive & 13 & 10.2 \\
\hline Engineer & 11 & 8.7 \\
\hline \multicolumn{3}{|l|}{ Work Experience } \\
\hline Less than 5 years & 47 & 37.0 \\
\hline $6-10$ years & 42 & 33.1 \\
\hline $11-15$ years & 12 & 9.4 \\
\hline $16-20$ years & 13 & 10.2 \\
\hline More than 20 years & 13 & 10.2 \\
\hline
\end{tabular}

\subsection{Item Measurement}

Based on stakeholder theory and systematic reviews of both conceptual and empirical previous studies, particularly in the context of SMEs, a set of questionnaires was developed to obtain valuable information relating to the current status of the implementation of SMP. Five constructs were used to measure this (cleaner production, eco-efficiency, employee relations, supplier relations, and customer relations). Respondents were asked to indicate the extent of the implementation of each item measurement for all constructs that were thought to be related to current practice in their organization, using a five-point scale, from 1 for strongly not implemented to 5 for strongly implemented.

Following responsible survey research practices, the questionnaire was validated by experts, consisting of academicians and industrial practitioners, through the administration of a pre-test and pilot studies to ensure the validity and reliability of the measurements. The feedback, comments and recommendations from the experts were considered to have improved the quality of the measures used in the actual survey. 


\section{RESULTS AND DISCUSSION}

Descriptive analysis was conducted to determine the extent of the implementation of SMP among the SMEs in the Malaysian manufacturing sector. The results are presented in Table 3. Mean scores lower than 3.00 indicate that SMP is has not been implemented, while those of 3.00 and above demonstrate that it has been implemented. Specifically, mean scores of 3.00 to 3.66 indicate a low extent of implementation, 3.67 to 4.33 show a moderate extent of implementation, and 4.34 to 5.00 indicate a high extent of implementation.

Table 3 Extent of SMP implementation results

\begin{tabular}{ccc}
\hline Sustainable Manufacturing Practice & Mean & Standard Deviation \\
\hline Cleaner production & 3.79 & 0.72 \\
Eco-efficiency & 3.78 & 0.75 \\
Employee relations & 4.04 & 0.65 \\
Supplier relations & 3.66 & 0.81 \\
Customer relations & 4.07 & 0.68 \\
\hline
\end{tabular}

Based on the five-point scale, the mean scores for SMP implementation ranged from 3.66 to 4.07, which indicates a low to moderate extent of implementation among the SMEs. The results of the study imply that although environmental initiatives are becoming an important part of the strategic planning of SMEs (Ramayah et al., 2013), there is still a lack of SMP implementation in operational and business activities. Many SMEs still consider the integration of environmental practices into business activities as something new (Moorthy et al., 2012). Those in the manufacturing sector are less active in sustainable management compared to larger firms (Omar \& Samuel, 2011). Unlike large firms, it can be more challenging for SMEs to implement sustainable initiatives, as a shortage of resources (Hsu et al., 2017), weak organizational management, and a lack of financial stability are common features for most of them (Raja Ghazilla et al., 2015).

Specifically, customer-oriented sustainable practice was the most common type of SMP implemented by SMEs (4.07). Many SMEs may choose to adopt sustainable strategies for customer-related reasons. The demand for green products or processes from customers, and customer collaboration in green initiatives, were identified as important drivers for the implementation of green practices in SMEs (Raja Ghazilla et al., 2015). SMEs may have two types of customer, namely individuals (the public) and other businesses (including private firms and government agencies). The growing consciousness of environmental protection among customers has forced SMEs to be more environmentally responsible. As many of the firms are suppliers to other businesses or firms, they face growing pressure from customers to incorporate environmental considerations into their networks in order to create a sustainable and responsible supply chain. In terms of being environmentally friendly and socially responsible with their customers, the results of the study reveal that Malaysian SMEs make moderate efforts to prevent products from causing danger to their customers; provide credible information about the products being supplied; integrate customer feedback into business activities; improve packaging based on environmental considerations; and implement environmentally friendly waste management systems and eco-labelling of products. Appendix A presents the mean values of all the item measurements of customer relations, as well as the other sustainable practices referred to in this study.

Employee-oriented sustainable practice is the second highest type of SMP implemented by Malaysian SMEs (4.04). In general, the results show that Malaysian SMEs practice employee relations at a moderate level. The responding firms demonstrated their concern about their employees' well-being through moderately guaranteeing observation of industrial safety 
regulations; fair payment of employees; care for employees' personal development; and support for their work-life balance.

Similarly, cleaner production and eco-efficiency have been moderately implemented. The respective mean values of 3.79 and 3.78 suggest that Malaysian SMEs have started to change from relying merely on pollution control and treatment strategies in handling environmental and other sustainability issues, to more proactive approaches. However, deeper analysis demonstrates that substantial changes or improvements need to be made, especially in internal recycling of materials; substituting non-environmentally friendly materials; and focusing on reducing energy and material consumption when designing products. Currently, these three sustainable practices have been adopted by SMEs, but with a low extent of implementation. In addition, the analysis shows a moderate extent of implementation of other sustainable efforts in cleaner production and eco-efficiency, such as acquiring clean technology/equipment; focusing on reducing energy and natural resource consumption in operations when designing processes; optimizing manufacturing processes in order to reduce solid waste and emissions; establishing environmental compliance and auditing programmes; and cross-functional cooperation for environmental improvements; the firms' efforts in relation to the environmental matters that have exceeded the requirements of the relevant regulations; and establishing total quality environmental management system.

On the other hand, supplier-oriented sustainable practice is the lowest type of SMP implemented by Malaysian SMEs. The mean score of 3.66 for this indicates that the responding firms have just started to formally practice environmental collaboration with their suppliers in order to improve their economic and environmental sustainability, as well as the sustainability of their suppliers. Substantial improvements need to be made by SMEs in choosing suppliers based on environmental criteria; guiding them to set up their own environmental programs; informing suppliers about the benefits of cleaner production and technologies; urging them to take environmental actions; and sending internal auditors to appraise the environmental performance of suppliers.

\section{CONCLUSION}

Empirical evidence from previous studies emphasizes that better economic performance of manufacturing firms, together with environmental and social sustainability, can be achieved by implementing SMP. This study has examined the extent of the implementation of SMP among SMEs in the Malaysian manufacturing sector. In general, the results of the analysis reveal that they have adopted a proactive approach to SMP in their operational and business activities, but at a low to moderate extent of implementation. Considering the uniqueness of SMEs, especially micro and small manufacturers, the lack of resources, organizational management and financial stability may explain the reasons for the insufficient implementation of pollution prevention approaches, such as cleaner production and eco-efficiency, as well as socially responsible practices related to employees, customers and suppliers. Customer-oriented sustainable practice is the most common type of sustainable practice implemented by the responding firms, followed by customer relations, cleaner production, eco-efficiency and supplier relations.

The study provides data and information regarding the current status of SMP implemented by SMEs in Malaysia and will a useful reference for salient stakeholders such as the government and industrial practitioners when making decisions and taking further action related to the strategies of nurturing, implementing and enforcing environmental protection and social wellbeing. Since this study is descriptive in nature and is focused on sustainable practices, it is suggested that future research should study the relationship or the impact of these practices on the sustainability performance of firms. 


\section{ACKNOWLEDGEMENT}

The authors wish to thank the Ministry of Higher Education Malaysia for funding this study under the Fundamental Research Grant Scheme (FRGS), S/O code 13261, and the Research and Innovation Management Centre, Universiti Utara Malaysia, Kedah for the administration of the study.

\section{REFERENCES}

Berawi, M.A., 2016. Accelerating Sustainable Infrastructure Development: Assuring Wellbeing and Ensuring Environmental Sustainability. International Journal of Technology, Volume 7(4), pp. 527-529

Bhanot, N., Rao, P.V., Deshmukh, S.G., 2015. Sustainable Manufacturing: An Interaction Analysis for Machining Parameters using Graph Theory. Procedia - Social and Behavioral Sciences, Volume 189, pp. 57-63

Cassells, S., Lewis, K., 2011. SMEs and Environmental Responsibility: Do Actions Reflect Attitudes?. Corporate Social Responsibility and Environmental Management, Volume 18(3), pp. 186-199

Ditlev-Simonsen, C.D., Wenstøp, F., 2013. How Stakeholders View Stakeholders as CSR Motivators. Social Responsibility Journal, Volume 9(1), pp. 137-147

DOSM (Department of Statistics Malaysia), 2011. SME Census 2011: Economic Census 2011

Freeman, E., Phillips, R., 2002. Stakeholder Theory: A Libertarian Defense. Business Ethics Quarterly, Volume 12(3), pp. 331-349

Freeman, R.E., 1984. Strategic Management: A Stakeholder Approach. Pitman, Boston

Hahn, T., Pinkse, J., Preuss, L. Figge, F., 2016. Ambidexterity for Corporate Social Performance. Organization Studies, Volume 37(2), pp. 213-235

Hami, N., 2015. Sustainable Manufacturing Practice and Sustainability Performance Mediated by Innovation Performance. PhD Dissertation, FKP, UTeM, Malacca

Hami, N., Yamin, F.M., Shafie, S.M., Muhamad, M.R., 2017. An Analysis of Sustainable Manufacturing Practices in Malaysian SMEs, In: ISoRIS 2017, Malacca, Malaysia

Hashim, H., 2013. Overview of SME Sector in Malaysia. In: the Malaysia-India SME Forum, Kuala Lumpur, Malaysia

Hsu, C.H., Chang, A.Y., Luo, W., 2017. Identifying Key Performance Factors for Sustainability Development of SMEs: Integrating QFD and Fuzzy MADM Methods. Journal of Cleaner Production, Volume 161, pp. 629-645

Jayal, A.D., Badurdeen, F., Dillon, O.W., Jawahir, I.S., 2010. Sustainable Manufacturing: Modeling and Optimization Challenges at the Product, Process and System Levels. CIRP Journal of Manufacturing Science and Technology, Volume 2(3), pp. 144-152

Khatri, J.K., Metri, B., 2016. SWOT-AHP Approach for Sustainable Manufacturing Strategy Selection: A Case of Indian SME. Global Business Review, Volume 17(5), pp. 1211-1226

Kim, S.T., 2010. Implementation of Green Supply Chain Management: Impact on Performance Outcomes in Small and Medium-Sized Electrical and Electronic Firms. PhD Dissertation, Nebraska University, USA

Koe, W.L., Omar, R., Sa'ari, J.R., 2015. Factors Influencing Propensity to Sustainable Entrepreneurship of SMEs in Malaysia. Procedia - Social and Behavioral Sciences, Volume 172, pp. 570-577

Korhonen, J., 2000. Completing the Industrial Ecology Cascade Chain in the Case of a Paper Industry: SME Potential in Industrial Ecology. Eco-Management and Auditing, Volume 7(1), pp. 11-20

Laurinkeviciute, A., Stasiskiene, Z., 2011. SMS for Decision Making of SMEs. Clean Technologies and Environmental Policy, Volume 13(6), pp. 797-807 
Moorthy, M.K., Yakob, P., Chelliah, M.K., Arokiasamy, L., 2012. Drivers for Malaysian SMEs to Go Green. International Journal of Academic Research in Business and Social Sciences, Volume 2(9), pp. 74-86

Nejati, M., Amran, A., 2013. Corporate Social Responsibility Terminologies in Small Businesses: Insights from Malaysia. Business Strategy Series, Volume 14(1), pp. 11-14

OECD (Organization for Economic Co-operation and Development), 2010. Eco-innovation in Industry: Enabling Green Growth

Omar, R., Samuel, R., 2011. Environmental Management amongst Manufacturing Firms in Malaysia. In: $3^{\text {rd }}$ Int. Symposium \& Exhibition in Sustainable Energy \& Environment, Malacca, Malaysia

Raja Ghazilla, R.A., Sakudarini, N., Abdul-Rashid, S.H., Ayub, N.S., Olugu, E.U., Musa, S.N., 2015. Drivers and Barriers Analysis for Green Manufacturing Practices in Malaysian SMEs: A Preliminary Findings. Procedia CIRP, Volume 26, pp. 658-663

Ramayah, T., Leen, J., Marimuthu, M., Omar, A., Mohamad, O., 2013. Green Manufacturing Practices and Performance among SMEs: Evidence from a Developing Nation. USA: IGIGlobal

SME Corporation Malaysia, 2016. SME Annual Report 2015/2016, SME Corp. Malaysia

Szekely, F., Knirsch, M., 2005. Responsible Leadership and Corporate Social Responsibility: Metrics for Sustainable Performance. European Management Journal, Volume 23(6), pp. 628-647

Wong, B.Y.L., More, E., 2016. Management of Corporate Social Responsibility in Hong Kong Small and Medium Enterprises. Journal of Global Responsibility, Volume 7(2), pp. 146162

Wooi, G.C., Zailani, S., 2010. Green Supply Chain Initiatives: Investigation on the Barriers in the Context of SMEs in Malaysia. International Business Management, Volume 4(1), pp. 20-27

Yahya, N., Nair, S.R., Piaralal, S.K., 2014. Green Practices Adoption Framework for Small and Medium Sized Logistics Firms in Malaysia. Sains Humanika, Volume 2(3), pp. 79-84

Yusoff, W.F.W., Adamu, M.S., 2016. The Relationship between Corporate Social Responsibility and Financial Performance: Evidence from Malaysia. International Business Management, Volume 10(4), 345-351 


\section{Appendix A}

Mean scores of item measurements of SMP implementation

\begin{tabular}{|c|c|c|c|}
\hline SMP & Item measurement & Mean & SD \\
\hline \multirow{6}{*}{$\begin{array}{l}\text { Cleaner } \\
\text { production }\end{array}$} & Substitution of non-environmental friendly materials & 3.65 & 1.08 \\
\hline & $\begin{array}{l}\text { Optimization of manufacturing processes to reduce solid } \\
\text { waste and emissions }\end{array}$ & 3.80 & 1.04 \\
\hline & $\begin{array}{l}\text { Process design focused on reducing energy and natural } \\
\text { resources consumption in operations }\end{array}$ & 3.79 & 1.01 \\
\hline & $\begin{array}{l}\text { Product design focused on reducing energy and materials } \\
\text { consumption }\end{array}$ & 3.66 & 1.04 \\
\hline & Acquisition of clean technology/equipment & 3.75 & 1.02 \\
\hline & $\begin{array}{l}\text { Good housekeeping practices (e.g., improvements in work } \\
\text { practices and maintenance) }\end{array}$ & 4.12 & 0.84 \\
\hline \multirow[t]{5}{*}{ Eco-efficiency } & Recycling of materials internal to the company & 3.56 & 1.12 \\
\hline & $\begin{array}{l}\text { Cross-functional cooperation for environmental } \\
\text { improvements }\end{array}$ & 3.76 & 0.98 \\
\hline & Total quality environmental management is in place & 4.06 & 0.89 \\
\hline & $\begin{array}{l}\text { Environmental compliance and auditing programs are in } \\
\text { place }\end{array}$ & 3.75 & 1.02 \\
\hline & $\begin{array}{l}\text { The company's efforts in relation to the environmental } \\
\text { matters have exceeded the requirements of the relevant } \\
\text { regulations }\end{array}$ & 3.76 & 0.95 \\
\hline \multirow{4}{*}{$\begin{array}{l}\text { Employee } \\
\text { relation }\end{array}$} & Guaranteed observation of industry safety regulations & 4.24 & 0.80 \\
\hline & Fair payment of employees & 4.16 & 0.81 \\
\hline & Care for employee's personal development & 4.16 & 0.82 \\
\hline & Supporting work-life balance & 3.98 & 0.79 \\
\hline \multirow{5}{*}{$\begin{array}{l}\text { Supplier } \\
\text { relation }\end{array}$} & Choice of suppliers by environmental criteria & 3.86 & 0.91 \\
\hline & $\begin{array}{l}\text { Guiding suppliers to set up their own environmental } \\
\text { programs }\end{array}$ & 3.72 & 0.91 \\
\hline & $\begin{array}{l}\text { Informing suppliers about the benefits of cleaner production } \\
\text { and technologies }\end{array}$ & 3.61 & 1.03 \\
\hline & Urging suppliers to take environmental actions & 3.63 & 1.05 \\
\hline & $\begin{array}{l}\text { Sending internal auditors to appraise environmental } \\
\text { performance of suppliers }\end{array}$ & 3.48 & 1.02 \\
\hline \multirow{6}{*}{$\begin{array}{l}\text { Customer } \\
\text { relation }\end{array}$} & Environmental friendly waste management & 3.94 & 0.97 \\
\hline & Environmental improvement of packaging & 4.09 & 0.89 \\
\hline & Eco labeling of products & 3.87 & 0.98 \\
\hline & Providing credible information about product biography & 4.16 & 0.83 \\
\hline & Integration of customer feedback into business activity & 4.10 & 0.79 \\
\hline & Prevention of products causing danger for customers & 4.28 & 0.81 \\
\hline
\end{tabular}

